\title{
Recognition and Analysis of Connected Transaction's Earnings Management in Letv Ecology
}

\author{
Wang Fushun \\ School of Business, Hunan University, Changsha 410000, China \\ 18390884327@163.com
}

Keywords: Letv Ecology; connected transaction; earnings management; case study

\begin{abstract}
Through financial strategy matrix, the paper firstly concludes Letv's problems on rapid expansion, single profits and capital shortage, indicating that the current financial status of Letv is difficult to support "Letv ecology" constructed by its management. It has earnings management motivation. Subsequently, through further analysis, it is found that Letv carried out earnings management of connected transaction by non-commercial purchase and sales and the means of loss "shifting" minority. Finally, this paper puts forward reasonable suggestions on how to improve the company's internal control system and standardize information disclosure of connected transaction.
\end{abstract}

\section{Summary of Connected Transaction}

There are various means of earnings management in listed companies, especially using non-explicit provisions of accounting policies and accounting estimation to manipulate profits through connected transactions. As the item of transferring assets or obligations incurred between listed companies and related parties, there is special interest relationship in connected transaction's main body. And with great complexity and concealment, it is easier to be used by listed companies as the means of earnings management.

Many companies in China are listed by the parent company's part of high-quality assets, the close relationship between the parent company and other subsidiaries in supply, production, sales, technology and labor service will inevitably generate a large number of connected transactions, providing opportunities for the management to realize profit manipulation. The earnings management of connected transaction only changes the profit amount on the book, and the actual profit amount will not change accordingly, which seriously reduces the credibility of the company's financial statements, damages the interest of the small and medium-sized investors, harms the function of optimizing resource allocation in securities market. It can also make investors lose confidence on China's capital market. Therefore, it has important practical significance on studying how to identify and prevent the connected transaction's earnings management of listed companies. 


\section{Case Introduction}

Letv, established in 2004, has attracted many investors relying on its Letv ecology of "platform + content + terminal + application" since the listing of A-shares in 2010. Its performance achieved a good result frequently, and at the same time, the stock price was also soaring. However, through analysis on the annual report of Letv in 2015, there was a strong suspicion on the earnings management of its connected transaction. It's not a myth in the capital market.

\section{Motivation Recognition of Earnings Management}

Table 1 Related Index of Financial Strategic Matrix of Letv

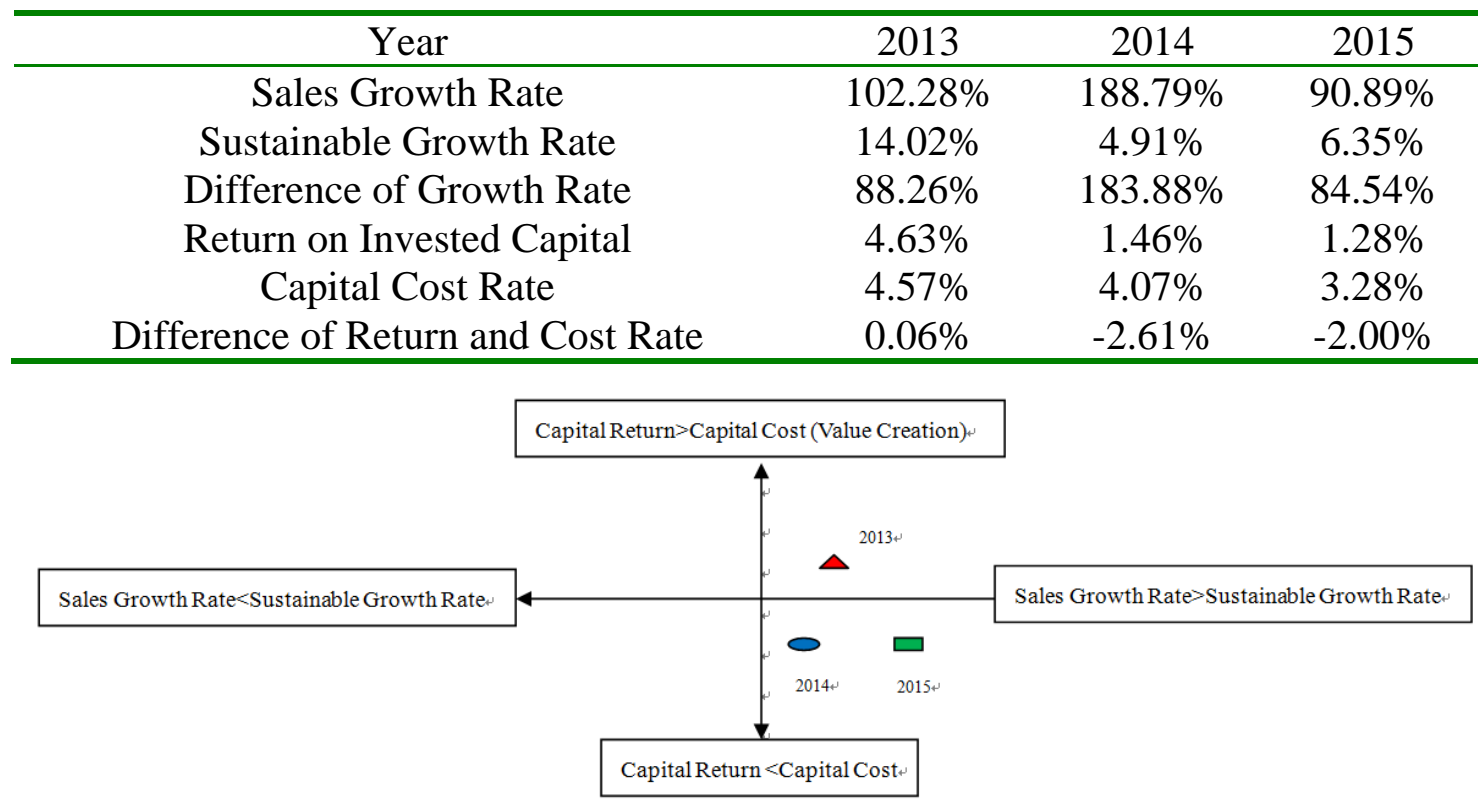

Fig. 1 Matrix of Financial Strategy of Letv in 2013-2015

According to analysis on financial strategy matrix of Letv in 2013-2015, the return rate of Letv's production and operation was slightly higher than capital cost rate in 2013. Although the operation results were not very outstanding, the profits obtained from operation were enough to compensate for the capital costs to support normal operation. However, the realized sustainable growth rate was lower than the actual sales growth rate. It meant that at this year, the funds available were not enough to support the continuous growth in the future and the enterprises should raise more funds by financing, so as to support continuous business growth. What's worse, the whole was in the fourth quadrant in 2014 and 2015, which shows a more serious problem. It meant that the operation of the enterprise didn't create value, it was still in a state of cash shortage. Due to the rapid expansion of business scale, it consumes the current corporate value. Coupled with the low profitability, business activities have failed to create value for the company, leading to a decline in the overall value of the company.

In order to conceal the company's actual worse financial status, smoothly access to financing and deliver positive news to investors, Letv has motivation to polishing finical report by using the means of earnings management. 


\section{Analysis on Earnings Management Means}

\subsection{High Coincidence of Related Parties on Purchase and Sales}

Through the analysis on the buyer and seller of connected transaction, it is found that there are a large number of two-way connected transactions existed in the connected transaction of Letv. In other words, Letv is not only the buyer of goods, but also the seller of products, which has formed the “internal circulation”.

The ultimate controller who accounts for the largest proportion in purchase and sales is Lefeng Mobile Hong Kong Co. Ltd. Under the circumstance that the product batches, number of goods, bills of in-out stock and other specific information have not been disclosed to outside, it is hard to judge whether the goods purchased and sold are the same batch. It may form non-commercial connected purchases and sales.

\subsection{Skillful Use of Merging Scope for Interest Delivery}

Table 2 Other Receivables of Letv (Parent Company Level) Unit: Million Yuan

\begin{tabular}{cccc}
\hline Company Name & $\begin{array}{c}\text { Nature of } \\
\text { Payment }\end{array}$ & $\begin{array}{c}\text { Ending } \\
\text { Balance }\end{array}$ & $\begin{array}{c}\text { Proportion in Ending Balance of } \\
\text { Other Receivables }\end{array}$ \\
\hline $\begin{array}{c}\text { Letv (Tianjin) Information } \\
\text { Technology Co. Ltd. }\end{array}$ & $\begin{array}{c}\text { Connected } \\
\text { Transaction }\end{array}$ & 1,590 & $60.39 \%$ \\
$\begin{array}{c}\text { Letv Zhixin Electronic Technology } \\
\text { (Tianjin) Co. Ltd. }\end{array}$ & $\begin{array}{c}\text { Connected } \\
\text { Transaction }\end{array}$ & 388 & $14.73 \%$ \\
$\begin{array}{c}\text { (Tibet) Letv Information } \\
\text { Technology Co. Ltd. }\end{array}$ & $\begin{array}{c}\text { Connected } \\
\text { Transaction } \\
\text { Connected } \\
\text { Letv Cloud Computing Co. Ltd. }\end{array}$ & 344 & $13.06 \%$ \\
Tetr Holdings (Beijing) Co. Ltd. & $\begin{array}{c}\text { Connected } \\
\text { Transaction }\end{array}$ & 11 & $10.42 \%$ \\
Total & - & 2,607 & $0.41 \%$ \\
\hline
\end{tabular}

Through the parent company report in 2015, it is found that the transaction between Letv and its non-wholly-owned subsidiaries became frequent. A huge amount had significant effect on operating income and net profit. Additionally, there were large amount of receivables on its related parties. There was a suspicion on Letv transferring profit from the subsidiaries to parent company.

According to Enterprise Accounting Standards No.30---Merged Financial Statement, if the listed main body of Letv directly controls the shareholding of its affiliated company, when the connected transaction happens, whether they are downstream or countercurrent, the unrealized internal transaction is needed to be offset and cannot become the income and profit. Therefore, in order to deliver profit to the listed main body, Letv doesn't choose to control the companies in the connected transaction and layout it in the "company controlled by the same controller". In addition, Letv, as a high-tech enterprise, enjoys $15 \%$ of tax rate preference while Letv Zhixin enjoys $25 \%$ of tax rate, so transferring the profit from subsidiary to the parent company can reduce large amount of taxes.

\subsection{Large Loss Displacement to Minority}

In 2015, 5 non-wholly-owned subsidiaries of Letv were all in a state of loss, including Letv Zhixin Electronic Technology (Tianjin) Co. Ltd., Letv Cultural Development (Beijing) Co. Ltd., Letv Cloud 
Computing Co. Ltd., Letv E-commerce (Beijing) Co. Ltd. and Letv Sports Culture Industry Development (Beijing) Co. Ltd., with net profits of about -731 million Yuan, -1 million Yuan, -100 million Yuan, -2 million Yuan and -27 million Yuan respectively. It should be of great concern.

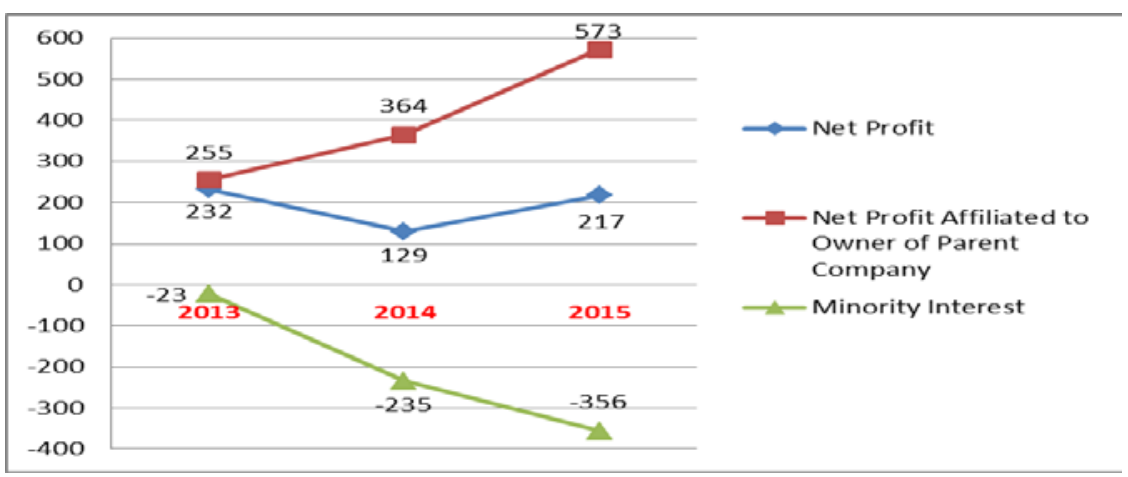

Fig. 2 Analysis on consolidated financial statements of Letv (Unit: Million Yuan)

From comparison of Letv's net profit and the net profit affiliated to owner of parent company in 2013-2015, it can be seen clearly that Letv's net profit actually fluctuated between 100 million Yuan and 200 million Yuan. After reaching the highest level of 232 million Yuan in 2013, it fell by 44.40\% in the second year and then rose again in 2015. However, in the last 3 years, no matter the net profit fell or rose, the net profit affiliated to owner of parent company remained unaffected and still kept rising with growth rate of about 50\%. In 2015, the net profit affiliated to the shareholders of listed companies was as high as 573 million Yuan, while the minority interests have been continuously fallen since 2010, and the loss of minority shareholders was 356 million Yuan in 2015. According to Net Profit=Net Profit Affiliated to Owner of Parent Company+Minority Interests, it can be deduced that the net profit affiliated to owner of parent company increases largely at the price for the huge loss of minority interests.

According to the Enterprise Accounting Standards No. 30-----Presentation of Financial Statements, when calculating the profit index of "net profit affiliated to owner of parent company", if the subsidiary is not wholly-owned, it should deduct the minority interests of subsidiaries. Using this standard, Letv diluted the net profit by the huge loss of minority shareholders of subsidiaries. With the arithmetic logic that negative plus negative equals to positive, Letv's net profit affiliated to owner of parent company is finally realized to be more. As for Letv, it shows that the subject of minority interests neglected by most people become an important adjustment lever that affects the net profit affiliated to owner of parent company.

\section{Inspiration}

\subsection{Improving Internal Control of Significant Connected Transaction}

As for Letv, Jia Yueting stands at a position with the largest shares all the time, and the ultimate controller of some affiliates is Jia Yueting or his brother Jia Yuemin. In order to prevent major shareholders from carrying out connected transaction by using their power to damage interest of small shareholders, when dealing with matters relating to connected transactions, the voting rights of major shareholders shall be restricted. The interest-related parties such as shareholders or directors in connected transactions should evade participation in the deliberation and voting. 


\subsection{Standardizing Information Disclosure of Connected Transaction}

As for the connected transaction between listed companies and associated enterprises and joint ventures, we shall focus on the situation where the buyer and seller are the same party, and refine content regulation of connected transaction. For example, a more detailed pricing process should be given on the pricing policy of transaction; subsequently, it shall expand the ways and channels of disclosure, so that investors can know the connected transaction more quickly and efficiently; Finally, it shall pay attention to the background information of related parties, such as the relationship between important shareholders.

The definition of related party in Administrative Measures for the Disclosure of Information of Listed Companies excludes listed companies' subsidiaries, associated enterprises and joint ventures, but the nature of neglected relevant transaction may has great significance on users, which facilitates the delivery of interests between the parent company and subsidiaries. Therefore, as for the connected transaction within the enterprise group, it shall start from perfecting Administrative Measures for the Disclosure of Information of Listed Companies, identitying the connected relationship broadly and strengthening the information disclosure between the parent company and subsidiaries referring to the above information disclosure requirements.

\subsection{Including Suspected Connected Transaction in the Key Auditing Items}

According to Enterprise Accounting Standards No. 30---Merged Financial Statement, when the subsidiaries suffer from excess loss, and there is no evidence that the minority shareholders have obligation, intention and ability to compensate for the excess loss, the shareholders shall take up all the excess loss of subsidiaries. At the same time, when judging whether it belongs to minority, it shall attach importance on the principle of substance over form. As Jia Yueting is not only the actual controller of Letv, but also the actual controller of minority, and he provides guarantee on the related payment between Zhixin and Letv, the minority interests cannot be separated from the net profits affiliated to the parent company completely. It shall disclose minority profit and loss on the key auditing items to improve the information content and decision-making usefulness to investors' decisions.

\section{References}

[1] Jiani Wu, Huaiqing Wang, Liang Liang, Shanshan Wang. A Concept Modeling Approach for Connected Transaction between the Listed Company and Their Parent Company[P]. E-Business and E-Government (ICEE), International Conference,2010.

[2] Shuji Rosey Bao, Krista B. Lewellyn. Ownership structure and earnings management in emerging markets-An institutionallized agency perspective[J]. International Business Review,2017 